\title{
Video Promosi Beasiswa Student Get Student Pada Universitas Raharja
}

\author{
Lusyani Sunarya $^{* 1}$, Maimunah ${ }^{2}$, Kris Budiyanto ${ }^{3}$ \\ ${ }^{1,2,3}$ Program Studi Teknik Informatika Fakultas Sains dan Teknologi Universitas Raharja \\ E-mail: ${ }^{1} \underline{\text { lusyani@ raharja.info }},{ }^{2} \underline{\text { maimunah@ raharja.info, }}, \underline{ }{ }^{3}$ kris@ raharja.info
}

\begin{abstract}
Abstrak
Peran promosi dalam memperkenalkan berbagailembagapendidikan khususnya pada universitas sangat berperan penting, agarmasyarakat dapat lebih mengenal pesan yang disampaikan.Hal itu dibuktikan dengan semakin berkembangnya jenis promosi yang diterapkan pada beberapa universitas saat ini, seperti video promosi, video company profile, banner, brosur dan lain-lain. Dengan adanya berbagai macam jenis promosi ini, maka suatu universitas memiliki kesempatan lebih luas untuk dikenal masyarakat. Begitu pula dengan Universitas Raharja yang salah satunya memiliki jenis promosi beasiswa Student Get Student (SGS).Universitas Raharja adalah universitas swasta dengan konsentrasi pengajaran manajemen dan ilmu komputer yang terletak pada Cikokol,Kota Tangerang. Namun program SGS ini masih belum memiliki video promosi tersendiri. Oleh karena itu video promosi SGS dibutuhkan agar program SGS semakin dikenal terutama oleh Mahasiswa Raharja itu sendiri dan tertarik mengikuti program beasiswa SGS ini. Dengan menerapkan metode pengumpulan data dan tahapankonsep produksi media yang terdiri dari tahapan pre-production, production dan post-production, dan juga menggunakan aplikasi penunjang, Adobe Photoshop CC 2017 dan Adobe After Effect CC 2017.Video Program beasiswa SGS ini diharapkan dapat membantu bagian pemasaran dalam meningkatkan target penerimaan mahasiswa baru setiap tahunnya.
\end{abstract}

Kata Kunci - Promosi, Program Beasiswa, Video Promosi.

\begin{abstract}
The role of promotion in introducing various educational institutions especially at universities is very important, so that the public can get to know the message conveyed. This is evidenced by the growing type of promotion applied at several universities today, such as promotional videos, company profile videos, banners, brochures and others. With the various types of promotions, a university has a wider opportunity to be known by the public. Likewise with Raharja University, one of which has a type of Student Get Student (SGS) scholarship promotion. Raharja University is a private university with a concentration in management and computer science teaching located in Cikokol, Tangerang City. However, the SGS program still does not have its own promotional video. Therefore the SGS promotional video is needed so that the SGS program is increasingly known, especially by Raharja Students themselves and interested in joining the SGS scholarship program. By applying data collection methods and stages of the concept of media production consisting of stages of pre-production, production and post-production. And also using supporting applications, Adobe Photoshop CC 2017 and Adobe After Effect CC 2017. Video This scholarship program SGS is expected to help the marketing department in increasing the target of new student admissions each year.
\end{abstract}

Keywords-Promotion, Scholarship Program, Promotion Video 


\section{PENDAHULUAN}

Media promosi merupakan suatu alat untuk mengkomunikasikan suatu produk/jasa/image/perusahaan ataupun yang lain untuk dapat lebih dikenal masyarakat lebih luas. Berkembangnya teknologi juga menjadikan media promosi yang semakin menarik, kreatif, dan inovatif, khususnya media promosi dalam bentuk video ${ }^{[1]}$.

Video tidak hanya menggunakan berbagai peralatan dan software akan tetapi dengan menyampaikan pesan yang tepat serta tepat dalam menggunakan kamera dan berbagai keperluan editing akan menghasilkan yang terbaik untuk media promosi ${ }^{[2]}$. Video promosi merupakan sarana terbaik untuk dapat meningkatkan jumlah murid ${ }^{[3]}$. Agar dapat meningkatkan minat calon mahasiswa/i baru, Raharja membutuhkan sarana promosi dan informasi, dalam bentuk media video yang saat ini banyak digunakan oleh lembaga atau instansi pendidikan sebagai wadah promosi ${ }^{[4]}$.

Universitas Raharja saat ini meningkatkan berbagai macam strategi promosi, agar dapat lebih dikenal masyarakat luas. Universitas Raharja adalah sebuah universitas swasta dengan konsentrasi pengajaran di bidang ekonomi dan komputer yang berlokasi di Jl. Jenderal Sudirman No.40, RT.002/RW.006, Cikokol, Kota Tangerang. Universitas Raharja memiliki visi yaitu pada tahun 2020, siap menjadi pelopor keilmuan berbasis IT yang membuka kesempatan bagi para lulusan yang berprestasi untuk dapat mengembangkan keilmuannya pada tingkat lanjutan serta memfasilitasi dalam memasuki dunia kerja di tingkat ASEAN.

Kegiatan promosi yang dilakukan pada Universitas Raharja saat ini, yaitu program beasiswa Student Get Student (SGS). Beasiswa SGS adalah program penerimaan mahasiswa baru yang dijalankan oleh seluruh Pribadi Raharja, dengan merekomendasikan calon mahasiswa/i baru untuk bergabung menjadi Pribadi Raharja. Kemudian bagi mahasiswa Raharja yang berhasil merekomendasikan calon mahasiswa/i baru menjadi Pribadi Raharja, maka mahasiswa tersebut akan mendapatkan beasiswa Student Get Student dan SGS Card.

Namun program SGS tersebut masih belum memiliki media informasi multimedia yang efektif, menarik dan lengkap mengenai SGS itu sendiri yang meliputi : apa itu SGS, bagaimana cara kerja SGS, apa yang didapatkan selama menjalankan program SGS, siapa saja yang boleh mengikuti program SGS, dan sebagainya. Oleh karena itu dibutuhkan sebuah media informasi multimedia berupa video promosi yang menerangkan program beasiswa SGS ini secara efektif dan efisien sebagai sebuah sarana penunjang promosi dan informasi untuk mendapatkan perhatian audience khususnya Mahasiswa Raharja dengan tujuan agar lebih banyak lagi mahasiswa/i baru yang bergabung pada Universitas Raharja serta mengikuti program beasiswa Student Get Student. Melalui video promosi $S G S$ ini, diharapkan jumlah mahasiswa yang ikut serta pada program ini akan lebih meningkat. Video promosi $S G S$ ini dapat digunakan pada saat pelaksana seminar resmi khusus mahasiswa Raharja, acara prospek, kegiatan workshop dan sebagainya.

Penelitian yang dilakukan oleh Desrianti, dkk (2019) ${ }^{[5]}$ berjudul "Video Profile Sebagai Media Penunjang Promosi Pada Sdk Penabur Gading Serpong”. Promosi merupakan suatu upaya yang digunakan untuk memasarkan produk atau jasanya kepada masyarakat, agar mereka lebih mengenal atau paham dengan produk atau jasa yang dipasarkan. Serta menyebutkan berdasarkan analisa kebutuhan maka diperlukan media promosi berupa video profile, untuk dapat menunjang informasi dan promosi yang lebih menarik serta efektif.

Penelitian yang dilakukan oleh Martono, dkk (2019) ${ }^{[6]}$ berjudul "Pembuatan VideoProfile Sekolah Menengah Atas Negeri 7 Kota Tangerang Selatan Berbasis Audio Visual Sebagai Media Informasi dan Promosi”. Penelitian ini bertujuan untuk membuat media promosi dan informasi SMA 7 Kota Tangerang Selatan yaitu, video profile dengan cara yang kreatif namun tetap efektif dan tidak memiliki biaya mahal.

Penelitian yang dilakukan oleh Apriani, dkk (2018) ${ }^{[7]}$ berjudul "Sarana Promosi Dan Informasi Sebagai Video Profile Smk Yuppentek 2 Curug Kabupaten Tangerang”. Promosi 
menggunakan teknologi komputer khususnya video akan meningkatkan daya tangkap informasi lebih baik karena mengikuti perkembangan teknologi.

Penelitian yang dilakukan oleh Wulandari, dkk $(2018)^{[8]}$ berjudul "Promosi Dan Informasi Pada Media Video Profile Sma Mandiri Balaraja". Dalam dunia pendidikan mempromosikan pendidikan sangatlah penting, promosi berperan menyebarkan informasi dan mempengaruhi calon siswa-siswi sehingga tertarik dengan sekolah tersebut.

Penelitian yang dilakukan oleh Budiarto, dkk (2018) ${ }^{[9]}$ berjudul "Media Promosi Dan Informasi Pada Pt. Gardena Karya Anugrah Berbentuk Video Company Profile". Penyebaran informasi tersebar melalui media cetak atupun media elektronik berbentuk multimedia, dari media itulah masyarakat dapat memperoleh informasi.

Penelitian yang dilakukan oleh Riyanto, dkk $(2017){ }^{[10]}$ berjudul "Media Video Feature Penunjang Promosi Pariwisata Kabupaten Pati - Jawa Tengah”. Pentingnya multimedia dalam penyampaian informasi memacu designer dan creator berkreatifitas untuk menciptakan bentukbentuk media informasi yang lebih komunikatif dan efisien yang dapat menarik untuk kalangan masyarakat.

\section{METODE PENELITIAN}

Beberapa metode penelitian yang digunakan penulis untuk mendapatkan data-data yang dibutuhkan dalam pembuatan Video Promosi Beasiswa Student Get Student Pada Universitas Raharja adalah : (1) Metode Wawancara. Metode ini dilakukan dengan melakukan tanya jawab atau wawancara kepada pihak stakeholder yaitu staff marketing Universitas Raharja dengan tujuan untuk mendapatkan data dan informasi yang dibutuhkan selama pembuatan video promosi SGS. (2) Metode Observasi yaitu metode yang dilakukan dengan melakukan observasi langsung pada Universitas Raharja itu sendiri lalu melakukan pencatatan secara sistematis. Observasi yang dilakukan berupa pemilihan tempat lokasi shooting yang sesuai dengan video promosi yang ingin dihasilkan. (3) Analisa Perancangan Media dengan menggunakan software penunjang video dan grafis yaitu Adobe After Effect CC 2017 dan Adobe Photoshop CC 2017 dan (4) Tahapan Konsep Produksi Media (KPM) yaitu tahapan yang dilakukan untuk mengorganisir proses produksi media agar memiliki konsep yang lebih jelas dan sistematis dan juga untuk menghasilkan produksi media menjadi lebih baik sesuai dengan keinginan stakeholder. Tahapan konsep produksi media yang paling sering dipakai dapat dilihat pada gambar di bawah ini.

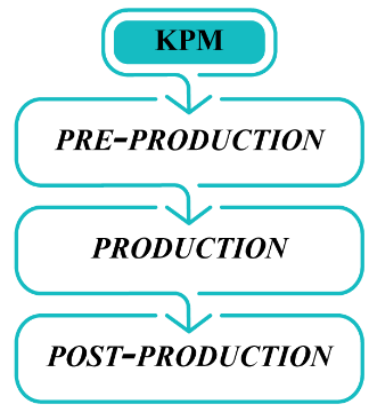

Gambar 1. Tahapan Konsep Produksi Media 


\section{HASIL DAN PEMBAHASAN}

\subsection{Pre-Production}

Pre-production adalah proses awal untuk mempersiapkan elemen-elemen yang akan terlibat dalam produksi video promosi ini. Pre-production diawali dengan ide tentang tema yang ingin ditampilkan, kemudian dilanjutkan dengan sinopsis atau ringkasan cerita video promosi dan diakhiri dengan mempersiapan atau setting alat untuk kebutuhan produksi. Berikut tahapantahapan pre-production yang digambarkan pada gambar dibawah ini :

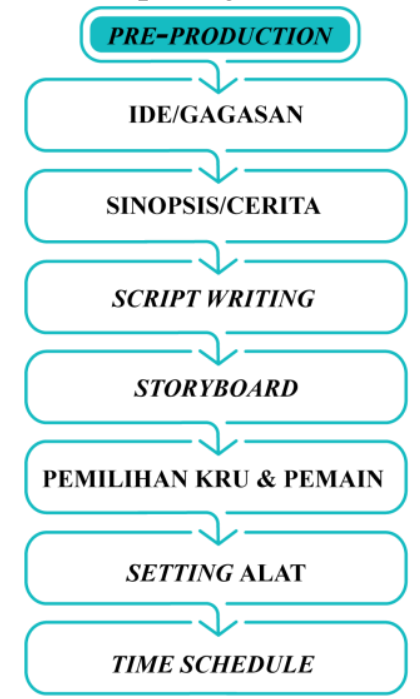

Gambar 2. Tahapan Pre-Production

\subsection{Ide/Gagasan}

Ide/gagasan merupakan langkah awal dalam membuat video promosi ini. Hampir keseluruhan ide/gagasan dalam video promosi ini diambil langsung dari lokasi Universitas Raharja. Hal itu dilakukan karena memang target video promosi ini adalah Mahasiswa Raharja itu sendiri sehingga dirasa akan lebih relevan apabila semua hal yang terkait adalah berada pada lingkungan Universitas Raharja.

\section{3. $\quad$ Sinopsis}

Secara umum sinopsis adalah ringkasan cerita dari suatu film atau video. Sinopsis digunakan untuk memahami secara cepat tentang maksud yang ingin disampaikan video tersebut. Dan berikut adalah sinopsis video promosi beasiswa student get student pada Universitas Raharja :

Narator wanita menjelaskan tentang SGS secara ringkas diiringi footage yang sesuai dengan narasi. Mengenai apa itu SGS, bagaimana cara mengikuti program SGS, dan cara klaim reward SGS. Setelah narasi tersebut rekaman video menampilkan review dari orang-orang yang sudah pernah mengikuti program SGS. Review tersebut dari mahasiswa yang sudah meraih reward tipe gold dan tipe platinum. Mahasiswa yang direview menjelaskan pengalaman serta manfaat saat mereka mengikuti program SGS berdasarkan jenis rewardnya, diakhir scene dijelaskan lebih detail mengenai kategori reward SGS tersebut dalam bentuk graphic animasi.

\section{4. $\quad$ Storyboard}

Storyboard merupakan sketsa gambar yang berhubungan dengan visual/gambar yang dilengkapi dengan keterangan terkait dengan sketsa gambar tersebut. Storyboard ini dipakai 
guna untuk kebutuhan shooting nantinya sehingga para kru memiliki gambaran sebelum melakukan shooting

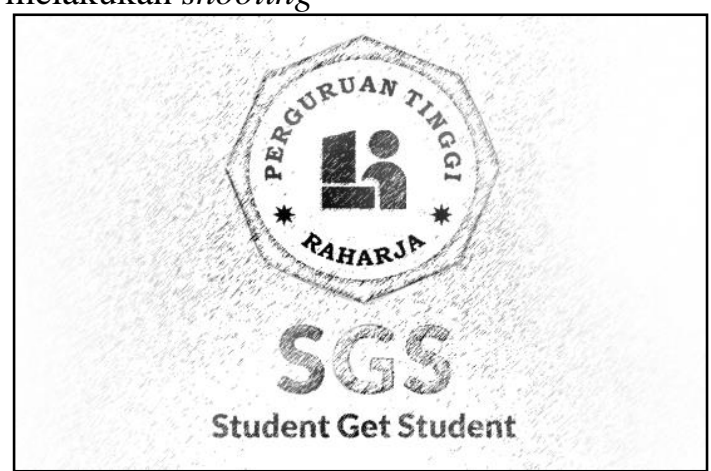

Gambar 3.

Bumper Opening Logo Perguruan Tinggi Raharja dan keterangan SGS

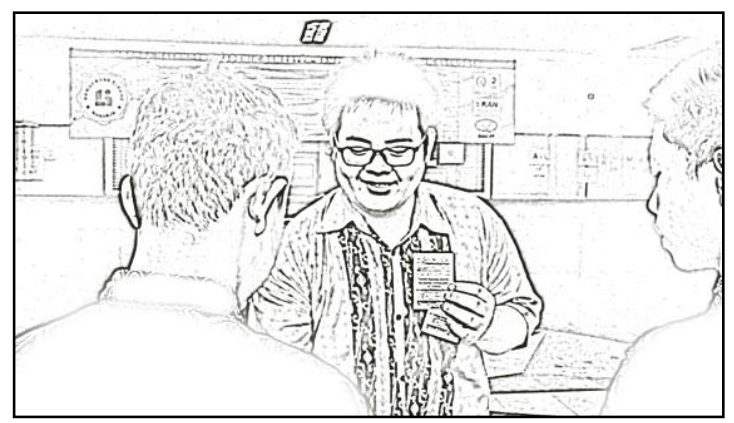

Gambar 5.

Peserta SGS mengajak calon mahasiswa

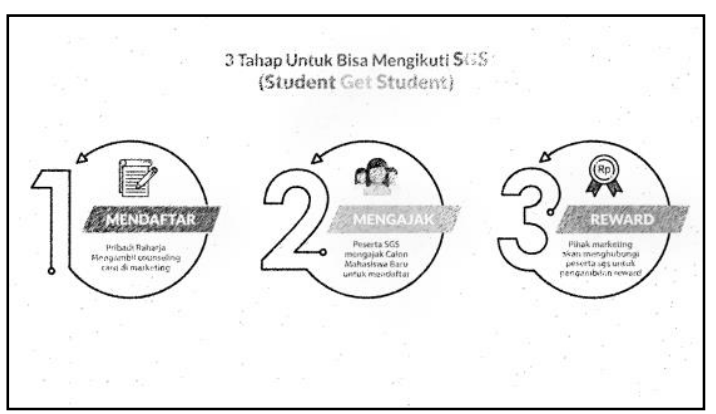

Gambar 7.

Tahapan untuk mengikuti SGS

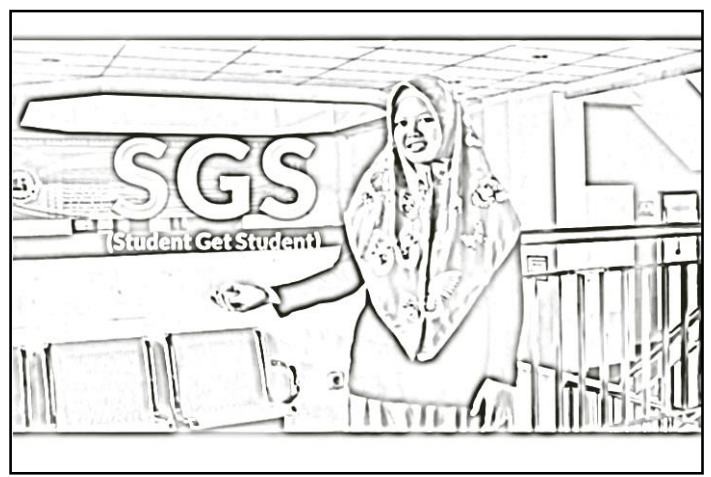

Gambar 4.

Presenter memperkenalkan program SGS

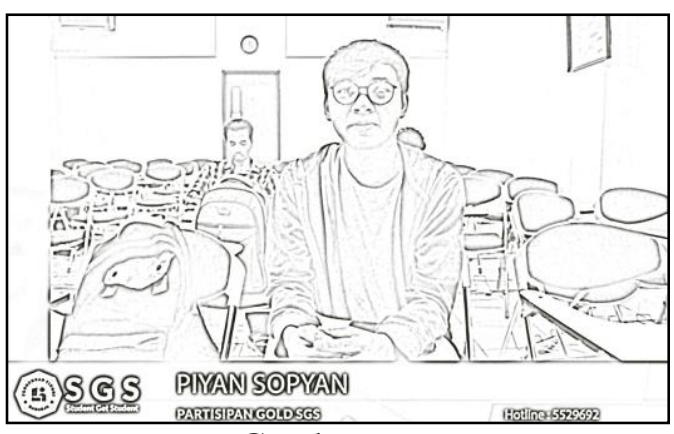

Gambar 6.

Wawancara peserta SGS

baru untuk bergabung di Universitas Raharja

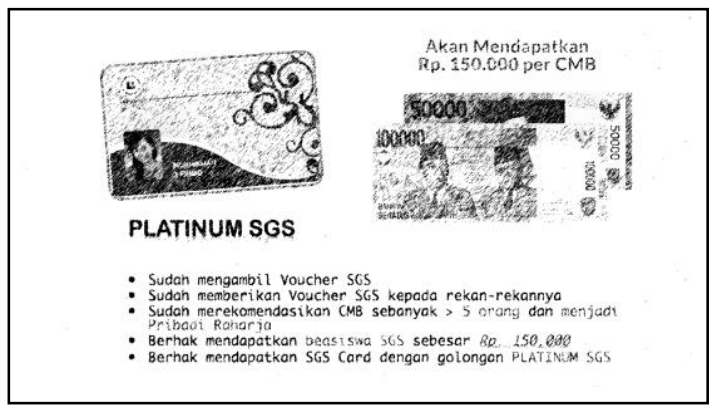

Gambar 8.

Keterangan beasiswa yang akan didapat pada program SGS 


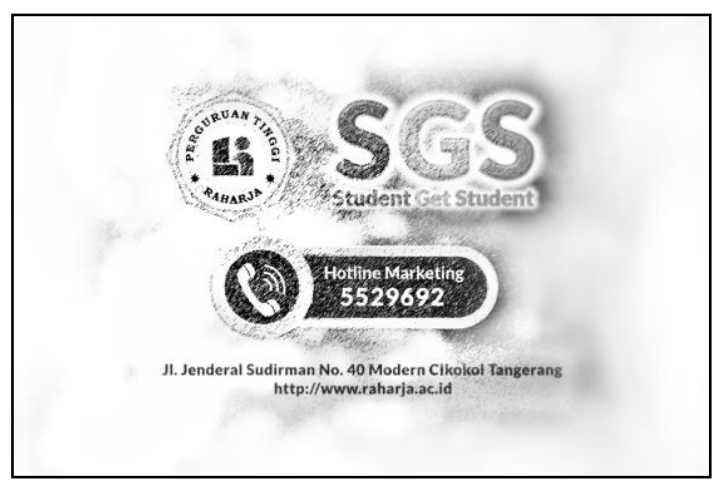

Gambar 9.

Closing Logo Perguruan Tinggi Raharja

dan informasi kontak

\subsection{Setting Alat}

Alat-alat yang digunakan pada video promosi $S G S$ adalah kamera Canon DSLR 800D, mikrofon Rode VideoMic Go, Tripod, dan lampu Lightning Camera 160 LED. Pengambilan gambar dilakukan sebagian pada Gedung Universitas Raharja dan sebagian pada area lingkungan Universitas Raharja.

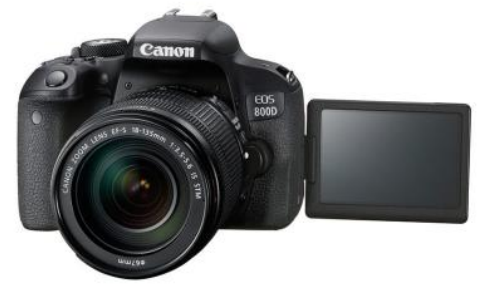

Gambar 10. Canon DSLR 800D

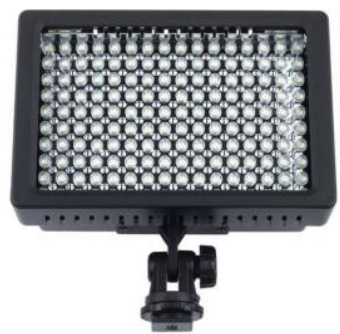

Gambar 12. Lightning Camera 160 LED

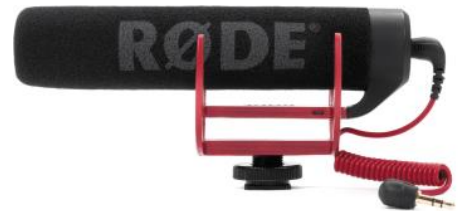

Gambar 11. Rode VideoMic Go

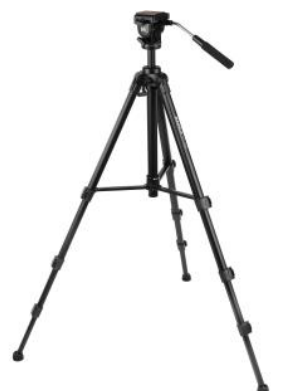

Gambar 13. Tripod

\subsection{Production}

Setelah mempersiapkan segala kebutuhan video promosi pada pre-production dan tahapan berikutnya yaitu production. Production adalah tahap dimulainya proses shooting video dan pengambilan gambar. Dan pada tahap ini juga sinopsis, storyboard dan scriptwriting yang telah dibuat sebelumnya dieksekusi oleh para pemain, kru, dan sutradara. 


\subsection{Post-Production}

Tahap akhir dalam pembuatan video promosi ini adalah Post-Production. Postproduction merupakan proses dimana keseluruhan hasil shooting diedit oleh editor video sesuai dengan storyboard sehingga menjadi hasil finishing video. Tahapan-tahapan pada postproduction adalah digitizing, editing, mixing, finishing, tahap keluaran dan segmen pasar.

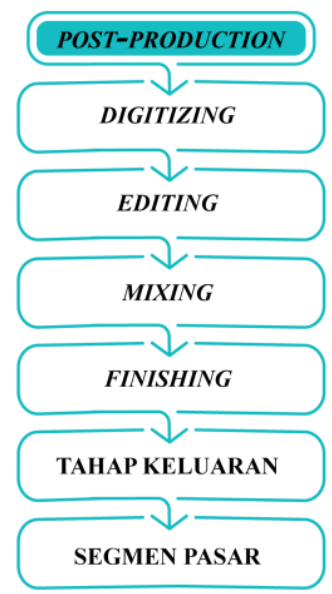

\subsection{Tampilan Isi}

Gambar 14. Tahapan Post-Production

Beberapa hal yang ditampilkan dalam video promosi beasiswa $S G S$ ini adalah pengenalan mengenai program $S G S$, wawancara dengan orang-orang yang telah mengikuti program $S G S$, tahapan agar bisa mengikuti program $S G S$, beasiswa $S G S$ yang didapat, dan yang terakhir adalah kontak informasi yang dapat dihubungi untuk informasi SGS lebih detail. Dibawah ini adalah tabel yang menunjukkan tampilan isi video yang dihasilkan dengan menggunakan tahapan konsep produksi media yang sudah dibahas sebelumnya.

Video Informasi SGS ini berdurasi 3 menit yang menjelaskan program Student Get Student secara jelas, singkat dan menarik.

\subsection{Jadwal Implementasi}

Video Informasi Beasiswa Student Get Student ini telah diImplementasikan oleh pihak Marketing Universitas Raharja pada tahun 2019 sebagai sarana informasi program marketing dalam mempromosikan SGS serta menunjang promosi Universitas Raharja

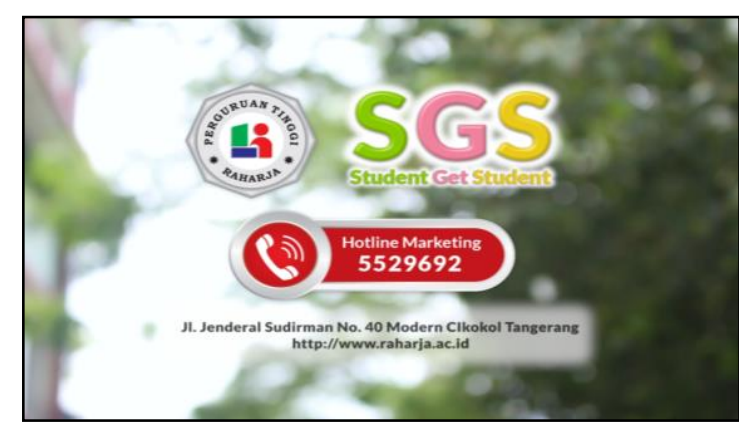

Gambar 15.

Bumper Opening Logo Perguruan Tinggi Raharja dan keterangan SGS

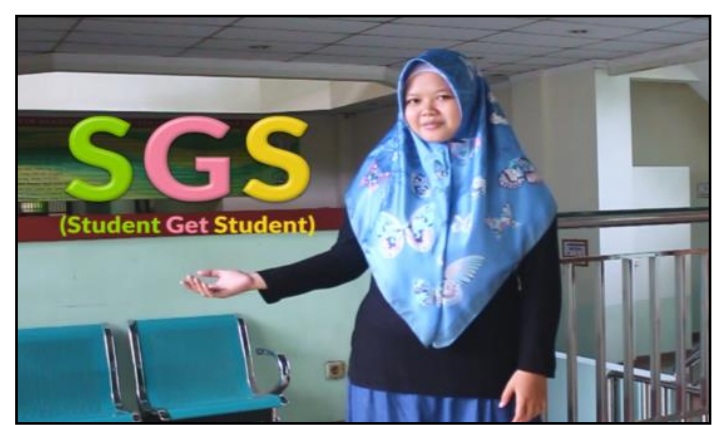

Gambar 16.

Presenter memperkenalkan program SGS 


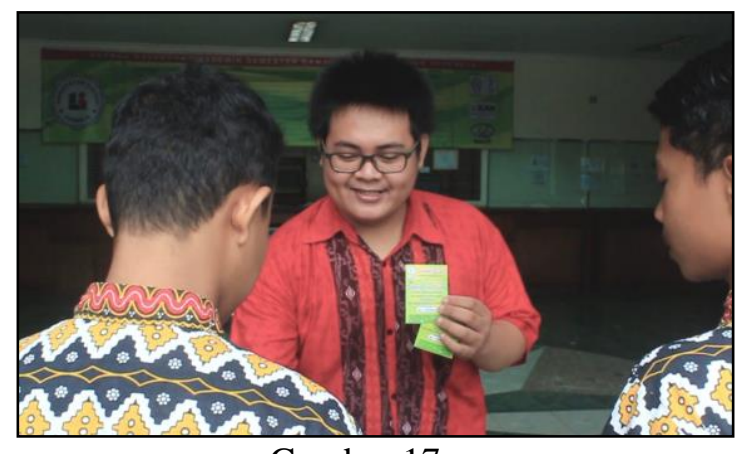

Gambar 17.

Peserta SGS mengajak calon mahasiswa baru untuk bergabung di Universitas Raharja

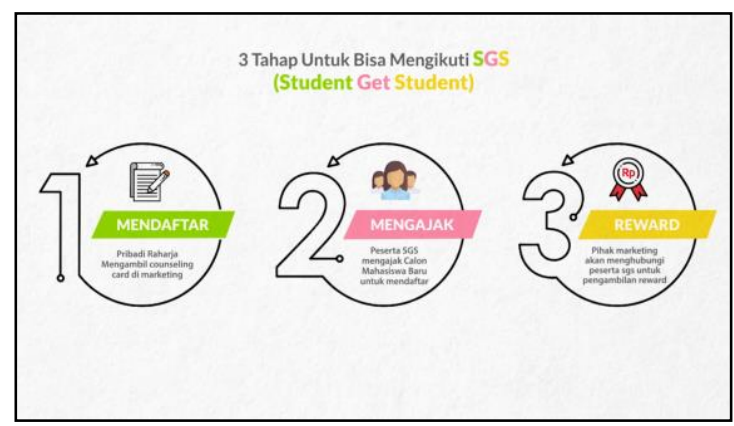

Gambar 19.

Tahapan untuk mengikuti SGS

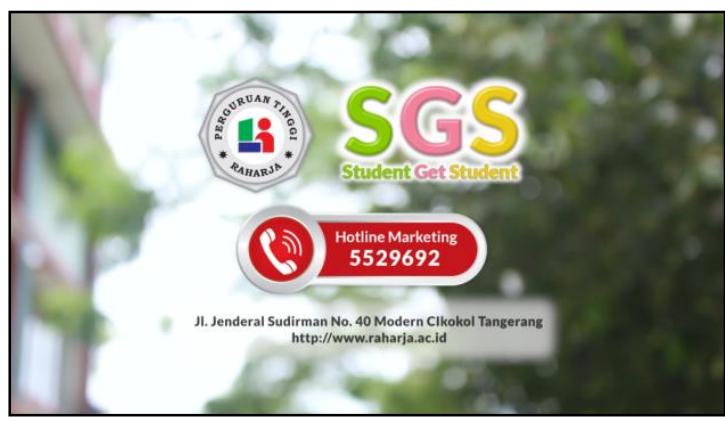

Gambar 21.

Closing Logo Perguruan Tinggi

Raharja dan informasi kontak

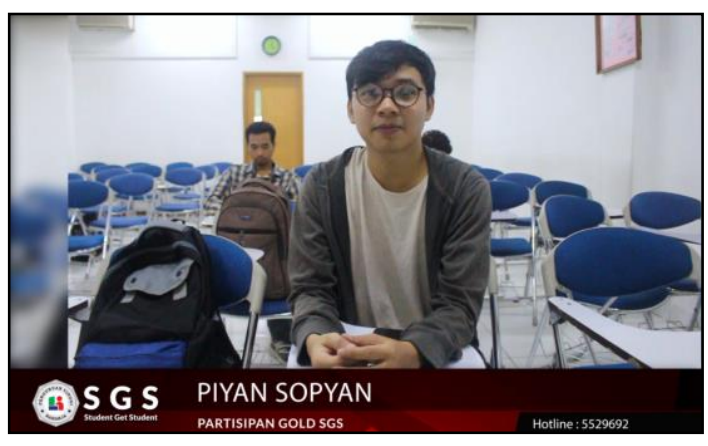

Gambar 18.

Wawancara peserta SGS

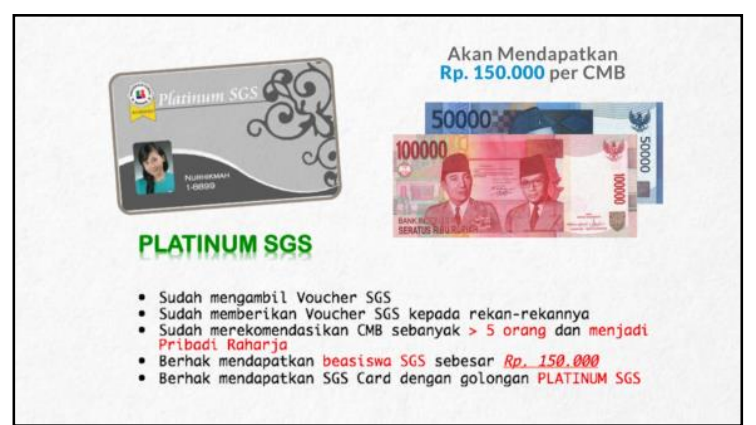

Gambar 20.

Keterangan beasiswa yang akan didapat pada program SGS 


\section{KESIMPULAN}

Video promosi yang baik adalah video promosi yang dapat memenuhi kebutuhan dan keinginan stakeholdernya dan target market stakeholder. Universitas Raharja membutuhkan media video promosi untuk menginformasikan dan mempromosikan program beasiswa Student Get Student (SGS) agar dapat lebih dikenal oleh Mahasiswa Raharja yang meliputi penjelasan mengenai apa itu program beasiswa $S G S$, siapa saja yang sudah pernah mengikuti program $S G S$, manfaat yang didapat apabila mengikuti program $S G S$, tahapan-tahapan apa saja yang harus dilakukan agar bisa mengikuti program $S G S$, dan sebagainya. Sehingga para mahasiswa Raharja dapat tertarik atau berminat untuk mencoba dan mengikuti program SGS. Video promosi beasiswa $S G S$ ini dibuat dengan narasi yang jelas dan sederhana agar dapat mudah dipahami, dan juga tentunya ditambahkan visual effect dan visualisasi yang dapat menarik minat untuk melihat, disertai juga backsound dan dubbing yang sesuai dengan visualisasi.Dengan adanya video promosi beasiswa $S G S$ ini, dapat menyediakan informasi dan promosi untuk program beasiswa $S G S$ yang efektif dan efisien bagi Universitas Raharja.Sehingga hasil akhir yang didapatkan dari penelitian ini adalah terbentuknya sebuah rancangan media promosi dan informasi berbentuk video promosi yang efektif dan efisien yang berdasarkan kebutuhan dan mampu meningkatkan tingkat minat mahasiswa Raharja untuk mengikuti program beasiswa $S G S$.

\section{SARAN}

Penulis menyarankan agar video promosi untuk program beasiswa SGS ini agar diperbaharui setiap periode tertentu demgam mengikuti kebutuhan masyarakat dan mahasiswa dan mengikuti perkembangan informasi agar tampilan suasana video promosi selalu fresh dan up to date.

\section{DAFTAR PUSTAKA}

[1] Abdillah, Fadhly, Damar Adhiguna dan Agus Sevtiana, 2017,Perancangan Video Profile Sebagai Media Promosistmik Cic Dengan Tehnik Motion Graphic menggunakan Perangkat Lunak Komputer Graphic, Jurnal Digit Vol.7 No.1, Cirebon, STMIK CIC.

[2] Rimayanti, Nita, Ana Yulianti, Belli Nasution dan Evawani Elysa Lubis, 2019,Pembuatan Video Profil Lembaga Penelitian dan Pengabdian Universitas Riau sebagai Media Promosi Berbasis Multimedia, IT Journal Research and Development Vol.3 No.2, Riau, Universitas Islam Riau.

[3] Anugerah, Percy Harris, Angga Hendrawan dan Christyan Budi Susilo, 2017,Perancangan Video Promosi Sekolah Musik indonesia Di Kota Surabaya, Journal ARTIKAVol.2 No.1, Surabaya, Institut Informatika Indonesia.

[4] Rifai, Danang, Erna Astriyani dan Upi Iindria, 2018,Pembuatan Video Company Profile Sebagai Penunjang Informasi dan Promosi Pada PT. Daiichi Elevator Indonesia, Technomedia Journal Vol.3 No.1, Tangerang, Perguruan Tinggi Raharja.

[5] Desrianti, Dewi Immaniar, Giandari Maulani dan Dana Krisdiana,2019, Video Profile Sebagai Media Penunjang Promosi Pada Sdk Penabur Gading Serpong, CCIT JournalVol.12 No.2, Tangerang, Universitas Raharja. 
[6] Martono, Triyono dan Roesmita Anggis Septiani 2018, Pembuatan Video Profile Sekolah Menengah Atas Negeri 7 Kota Tangerang Selatan Berbasis Audio Visual Sebagai Media Informasi dan Promosi,Technomedia Journal Vol.3 No.1, Tangerang, Perguruan Tinggi Raharja.

[7] Apriani, Desy, Rosdiana dan Asriyani 2018, Sarana Promosi Dan Informasi Sebagai Video Profile Smk Yuppentek 2 Curug Kabupaten Tangerang, Journal CICES Vol.4 No.2, Tangerang, STMIK Raharja.

[8] Wulandari, Ria, Achmad Rachmat dan Bobby Aditya Nugraha 2018, Promosi Dan Informasi Pada Media Video Profile Sma Mandiri Balaraja,Journal CICES Vol.4 No.2, Tangerang, STMIK Raharja.

[9] Budiarto, Mukti, Ulis Bella dan Nita Yuliania 2018, Media Promosi Dan Informasi Pada Pt. Gardena Karya Anugrah Berbentuk Video Company Profile,Journal CICES Vol.4 No.2, Tangerang, STMIK Raharja.

[10] Riyanto, Slamet, Dany Setiawan dan Aviv Rivaldi 2017, Media Video Feature Penunjang Promosi Pariwisata Kabupaten Pati - Jawa Tengah,Journal CICES Vol.3 No.2, Tangerang, STMIK Raharja. 